\title{
Malignant Triton tumour exhibits a complete expression pattern of nuclear retinoid and rexinoid receptor subtypes
}

\author{
Július Brtko ${ }^{1}$, Daniela Sejnová2 , Slavomíra Ondková ${ }^{1}$ and Dana Macejová ${ }^{1}$ \\ ${ }^{1}$ Institute of Experimental Endocrinology, Slovak Academy of Sciences, Bratislava, Slovakia; E-mail: Julius.Brtko@savba.sk \\ ${ }^{2}$ Department of Pediatric Hematology and Oncology, University Children's Hospital, Bratislava, Slovakia
}

Malignant peripheral nerve sheath tumours (MPNST) arise from Schwann cells or within existing neurofibromas and have a strong association with type 1 neurofibromatosis. MPNST with rhabdomyosarcomatous differentiation is also known as malignant Triton tumour (MTT) (Stasik and Tawfik 2006). MTT is aggressive tumour with bad prognosis. In 1932, Mason was the first one to describe rhabdomyoblasts in a peripheral-nerve tumour. The term "Triton tumour" was first described by Woodruff et al. in 1973. It is an extremely rare tumour, with less than 100 cases documented world-wide, and less than 10 in the mediastinum (Cano et al. 2006).

Patients with MTT are usually younger than age 35 (Yimaz et al. 2004). Köstler et al. (2003) reported a 26-yearold patient diagnosed with MTT who developed multiple recurrences despite repeated aggressive surgery, chemo- and radiotherapy during an 8-year period. Northern blotting analysis of an excised in-transit metastasis had revealed expression of retinoid receptors $\alpha$ and $\gamma$, and the patient received experimental treatment with retinoid isotretinoin and interferon- $\alpha$ for one year and remained without any evidence of disease for more than three years (Köstler et al. 2003).

Retinoids, rexinoids and their biologically active derivatives are involved in a complex arrangement of physiologi$\mathrm{cal}$ and developmental responses in many tissues of higher vertebrates. Both retinoids and rexinoids are either natural or synthetic compounds related to retinoic acids that act through interaction with two basic types of nuclear receptors belonging to the nuclear receptor superfamily: All-trans retinoic acid receptors, known as nuclear retinoid receptors (RAR $\alpha, R A R \beta$, and RAR $\gamma$ ) and retinoid X receptors (RXR $\alpha$, $\mathrm{RXR} \beta$ and $\mathrm{RXR} \gamma$ ) play an important role within the cell nucleus as retinoid-inducible transcription factors. Retinoids inhibit carcinogenesis, suppress premalignant epithelial lesions and tumour growth and invasion in a variety of tissues.

Correspondence to: Július Brtko, Institute of Experimental Endocrinology, Slovak Academy of Sciences, Bratislava, Slovakia E-mail: Julius.Brtko@savba.sk
Natural and synthetic retinoids exert important biological effects due to their antiproliferative and apoptosis-inducing effects. They are also known to cause redifferentiation or to prevent further dedifferentiation of various tumour tissues (Brtko and Thalhamer 2003; Brtko 2007).

Here, we report the case of a 12 -year-old boy in Slovakia who was admitted to the University Children's Hospital with a pain on the right side of his thorax. CT demonstrated tumour with the size of $58 \times 53 \mathrm{~mm}$ originating from the structure of the side of thorax and osteodystrofe changes of $3^{\text {rd }}$ and $4^{\text {th }}$ costae with no metastasis. Tumour was subsequently excised surgically with partially resection $3^{\text {rd }}$ and $4^{\text {th }}$ costae. The pathological examination after surgery confirmed MTT with focal myeloblastic differentiation. The patient underwent chemotherapy according to the protocol SIOP MMT 95 (vincristine, ifosfamide, actinomycin D, etoposide, carboplatin, epirubicin), which was completed in 27 weeks. Three months after the completion of chemotherapy, CT has shown the first local relapse and tumour $(50 \times 60 \mathrm{~mm})$ appearing was originating from $3^{\text {rd }}$ costae and adhered to lungs, which was totally excised surgically. Histologically, it was confirmed relapse of MTT with high malignancy. The second line of chemotherapy comprised treatment with Topotecan and Endoxan. After that second cycle of chemotherapy, radiation therapy was added to the same region in TD 56 Gy and paraspinalis on the right side 20 Gy. Later on, CT and MRI of abdomen confirmed mass to all three parts of pancreas - largest was in head, which caused icterus of obstruction of biliaries ducts, which lead to laparotomy with biopsy and cholecystoduodenoanastomosis. Histologically, the second metastatic relapse of MTT with higher portion of component rhabdomyosarcoma corresponding to embryonal rhabdomyosarcoma has been confirmed. The $3^{\text {rd }}$ line of chemotherapy for the second relapse was performed according to the protocol CWS 91 (Cisplatin and Dacarbazine). Patient underwent two cycles of chemotherapy without any effect, moreover, progression of metastases in abdomen wall was observed. 


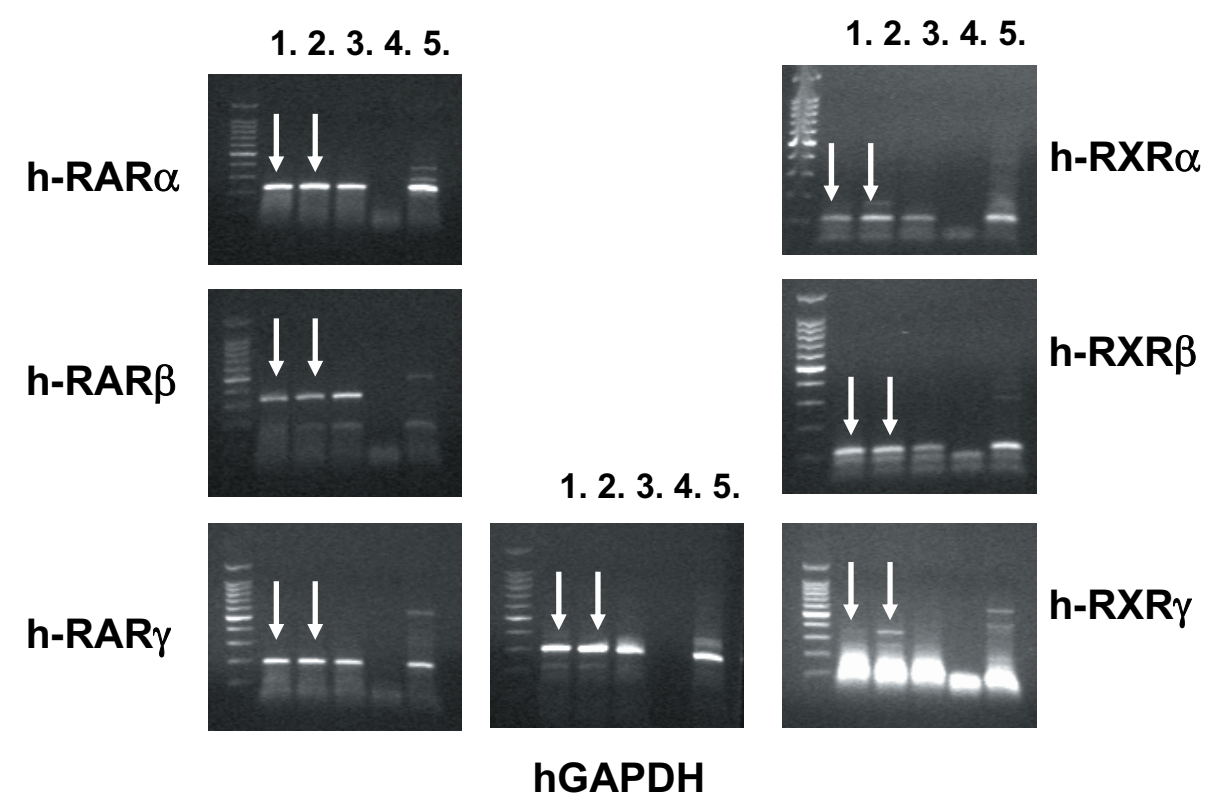

Figure 1. Expression of human nuclear retinoid receptors (h-RAR $\alpha, h-R A R \beta$, h-RAR $\gamma$ ) and nuclear retinoid X receptors (h-RXRa, h$\mathrm{RXR} \beta$, h-RXR $\gamma$ ) in the Triton tumour localized in the neck (1) and abdomen (2). 3, positive control - human thyroid tissue; 4, negative control; 5, positive control - human peripheral blood mononuclear cells.

At the stage of metastasectomy, the MTT tissues have been analyzed in order to get information about expression of all known subtypes of nuclear retinoid and nuclear retinoid $\mathrm{X}$ receptors mediating the effects of retinoic acids at the nuclear/cellular level. Determination of mRNA levels encoding all subtypes of nuclear retinoid receptors (RAR $\alpha, R A R \beta, R A R \gamma$ ) and nuclear retinoid $X$ receptors (RXR $\alpha, \operatorname{RXR} \beta, \mathrm{RXR} \gamma$ ) has been performed by the reverse transcription and subsequent PCR analyses according to Kimura et al. (2002). The band intensities were measured using the STS 6220I Documentation System (Ultralum, USA) and normalized to the band intensity of PCR product corresponding to the house keeper gene GAPDH. As shown in Fig. 1, both the MTT tissue excised from the patient neck or abdomen expressed all subtypes of RARs or RXRs. Since, retinoid receptors play a role as ligand-activated, DNAbinding, trans-acting, transcription-modulating proteins involved in a general molecular mechanism responsible for transcriptional responses in target genes, retinoids and/or rexinoids might thus represent a potentially powerful alternative to described chemotherapeutic treatments of advanced stages of MTT. Therefore, experimental palliative chemotherapy with 13-cis retinoic acid and interferon a has been indicated. After 6 weeks of that therapy, the next progression of MTT growth has been observed. The subsequent $4^{\text {th }}$ chemotherapy cycle with Cisplatin and Dacarbazin have been shown ineffective and patient died after 34 month of the above treatment.
In conclusion, our goal was to introduce a novel diagnostic approach in clinical oncology based on analyses of expression of retinoid and rexinoid receptors in MTT in relation to potentiality of retinoic acid and its derivatives exploitation in tumour therapy. MTTs are in general infrequent, those found in the head and neck and the upper or lower extremities have a better prognosis than those in the retroperitoneum, buttock, or trunk. It is not clear whether this variation is due to a difference in tumour grade, stage, or resectability, or whether it is a consequence of tumour therapy (Isla et al. 2000).

Ethics approval: The research followed the tenets of the Declaration of Helsinki and informed consent was obtained from the patient and his mother prior to sample collection for research with residual tumour tissue.

Acknowledgements. This research was supported predominantly by the grant APVV No. 0120-07, partly by the Centre of Excellence grant and the VEGA grant No. 2/0022/08.

\section{References}

Brtko J., Thalhamer J. (2003): Renaissance of the biologically active vitamin A derivatives: established and novel directed therapies for cancer and chemoprevention. Curr. Pharm. Des. 9, 2067-2077; doi:10.2174/1381612033454144

Brtko J. (2007): Retinoids, rexinoids and their cognate nuclear receptors: character and their role in chemoprevention of 
selected malignant diseases. Biomed. Pap. Med. Fac. Univ. Palacky Olomouc Czech Repub. 151, 187-194

Cano J. R., Algar F. J., Álvarez A., Salvatierra A. (2006): Triton tumor of the left sympathetic nerve. Interact. Cardiovasc. Thorac. Surg. 5, 790-791; doi:10.1510/icvts.2006.136994

Isla A., Gutierrez M., Casillas M., Gil J. L. (2000): Malignant triton tumor in the thoracic spine. Childs Nerv. Syst. 16, 256-259; doi:10.1007/s003810050509

Kimura Y., Suzuki T., Kaneko C., Darnel A. D., Moriya T., Suzuki S., Handa M., Ebina M., Nukiwa T., Sasano H. (2002): Retinoid receptors in the developing human lung. Clinical Science 103, 613-621

Köstler W. J., Amann G., Grunt T. W., Singer C. F., Schneider S. M., Brodowicz T., Tomek S., Zielinski C. C. (2003): Recurrent malignant Triton tumour: first report on a long time survivor. Oncol. Rep. 10, 533-535
Stasik C. J., Tawfik O. (2006): Malignant peripheral nerve sheath tumor with rhabdomyosarcomatous differentiation (malignant triton tumor). Arch. Pathol. Lab. Med. 130, 1878-1881

Yimaz M. R., Bek S., Bekmezci T., Gökduman C., Solak A. A. S. (2004): Malignant triton tumor of the lumbar spine. Spine 29, E399-401; doi:10.1097/01.brs.0000138308.56051.c7

Woodruff J. M., Chernik N. L., Smith M. C., Millet W. B., Foote F. W. (1973): Peripheral nerve tumor with rhabdomyosarcomatous differentiation. Cancer 32, 426-439; doi:10.1002/1097-0142(197308)32:2<426:: AID-CNCR2820320221>3.0.CO;2-W

Received: November 13, 2009

Final version accepted: December 7, 2009 